\title{
Network-based gene prediction for Plasmodium falciparum malaria towards genetics-based drug discovery
}

\author{
Yang Chen ${ }^{2}$, Rong $\mathrm{Xu}^{1^{*}}$ \\ From The International Conference on Intelligent Biology and Medicine (ICIBM) 2014 \\ San Antonio, TX, USA. 04-06 December 2014
}

\begin{abstract}
Background: Malaria is the most deadly parasitic infectious disease. Existing drug treatments have limited efficacy in malaria elimination, and the complex pathogenesis of the disease is not fully understood. Detecting novel malaria-associated genes not only contributes in revealing the disease pathogenesis, but also facilitates discovering new targets for anti-malaria drugs.

Methods: In this study, we developed a network-based approach to predict malaria-associated genes. We constructed a cross-species network to integrate human-human, parasite-parasite and human-parasite protein interactions. Then we extended the random walk algorithm on this network, and used known malaria genes as the seeds to find novel candidate genes for malaria.

Results: We validated our algorithms using 77 known malaria genes: 14 human genes and 63 parasite genes were ranked averagely within top $2 \%$ and top $4 \%$, respectively among human and parasite genomes. We also evaluated our method for predicting novel malaria genes using a set of 27 genes with literature supporting evidence. Our approach ranked 12 genes within top 1\% and 24 genes within top 5\%. In addition, we demonstrated that topranked candied genes were enriched for drug targets, and identified commonalities underlying top-ranked malaria genes through pathway analysis. In summary, the candidate malaria-associated genes predicted by our data-driven approach have the potential to guide genetics-based anti-malaria drug discovery.
\end{abstract}

\section{Background}

Malaria is the most deadly parasitic infectious disease, which killed 627,000 people and caused 482,000 childhood deaths worldwide in 2012 [1]. Existing drug treatments show limited efficacy in malaria elimination [2-6]. Detecting the novel genetic basis for malaria not only reveals the disease pathogenesis, but also facilitates discovering new targets for anti-malaria drugs [7-11].

The pathogen causing malaria is the Plasmodium species. After being injected by mosquitos into human skin, these parasites infect the liver and multiply using the host's cell resources. Then they invade the red blood cells and cause

\footnotetext{
* Correspondence: rxx@case.edu

'Department of Epidemiology and Biostatistics, Case Western Reserve University, Cleveland, OH, USA

Full list of author information is available at the end of the article
}

the disease symptoms [12-14]. In both the liver and blood stage, the parasites trigger the host's innate immune responses and remodel the host cells to survive from the immune responses [15-19]. The complex pathogenesis of malaria involves both human and parasite genomes [20-24], and is not fully understood yet [25-27].

Studies of the human-parasite protein interactions have provided insights into the molecular signatures for malaria-specific host immune responses [20,28,29]. For example, studies show that the parasite protein PfEMP1 binds the human protein CD36 [30-32] and ICAM1 [33-35], which play critical roles in the adhesion of the infected red blood cells to the endothelial cells, and eventually lead to the disruption of bloodbrain barrier in cerebral malaria patients [36,37]. Another example shows that the PfRh family of proteins in the parasites directly 
interacting with the human protein CR1 during the invasion of red blood cells, and CR1 has the potential to become the target of blood-stage vaccines $[38,39]$.

Currently, large-scale data have been accumulated on the human genome, parasite genome and their interactions. Integration and systematic analysis of the cross-species genomic data may lead to novel discoveries in genetic basis of malaria. In this study, we designed a data-driven approach to infer novel malariaassociated genes. Recent computational disease gene discovery algorithms have shown great potential in predicting disease causes [40-48]. They exploited the protein interactome in human genome and assumed that genes related to a disease phenotype tend to be located in a neighborhood in the proteinprotein interaction network [49]. However, traditional methods are not sufficient for predicting genes for malaria, which naturally involves human-parasite protein interactions. Our approach represented the interacting human and parasite genomes with a heterogeneous network. We prioritized genes that are functionally related to the known malaria genes in the heterogeneous network and investigated if the top-ranked genes have the potential to guide drug discovery for malaria. We made our results publicly accessible at nlp.case.edu/public/data/malaria.

\section{Methods}

Our experiment work flow is depicted in Figure 1 and consists of two steps: (1) prioritize genes through network analysis and (2) analyze the result. We first constructed separate genetic networks for human genome and parasite genome, and then connected them with host-pathogen protein interactions. We used genes that are known to be associated with malaria as the seeds and applied a random-walk based algorithm to rank genes in the crossspecies network. To validate our method in prioritizing malaria genes, we performed a "leave-one-out" cross validation analysis and examined the ranks of a set of malaria genes extracted from literature. Then we evaluated if the top-ranked genes are druggable. Finally, we analyzed the functions of the prioritized genes by extracting pathways on the basis of gene ranking.

\section{Construct cross-species gene network}

We constructed the genetic network for human and Plasmodium falciparum (the species that causes the most dangerous form of malaria) from the STRING [50,51] database. STRING includes gene relationships over a thousand species from four sources:protein-protein interactions (PPIs) databases, PPIs mined from literature

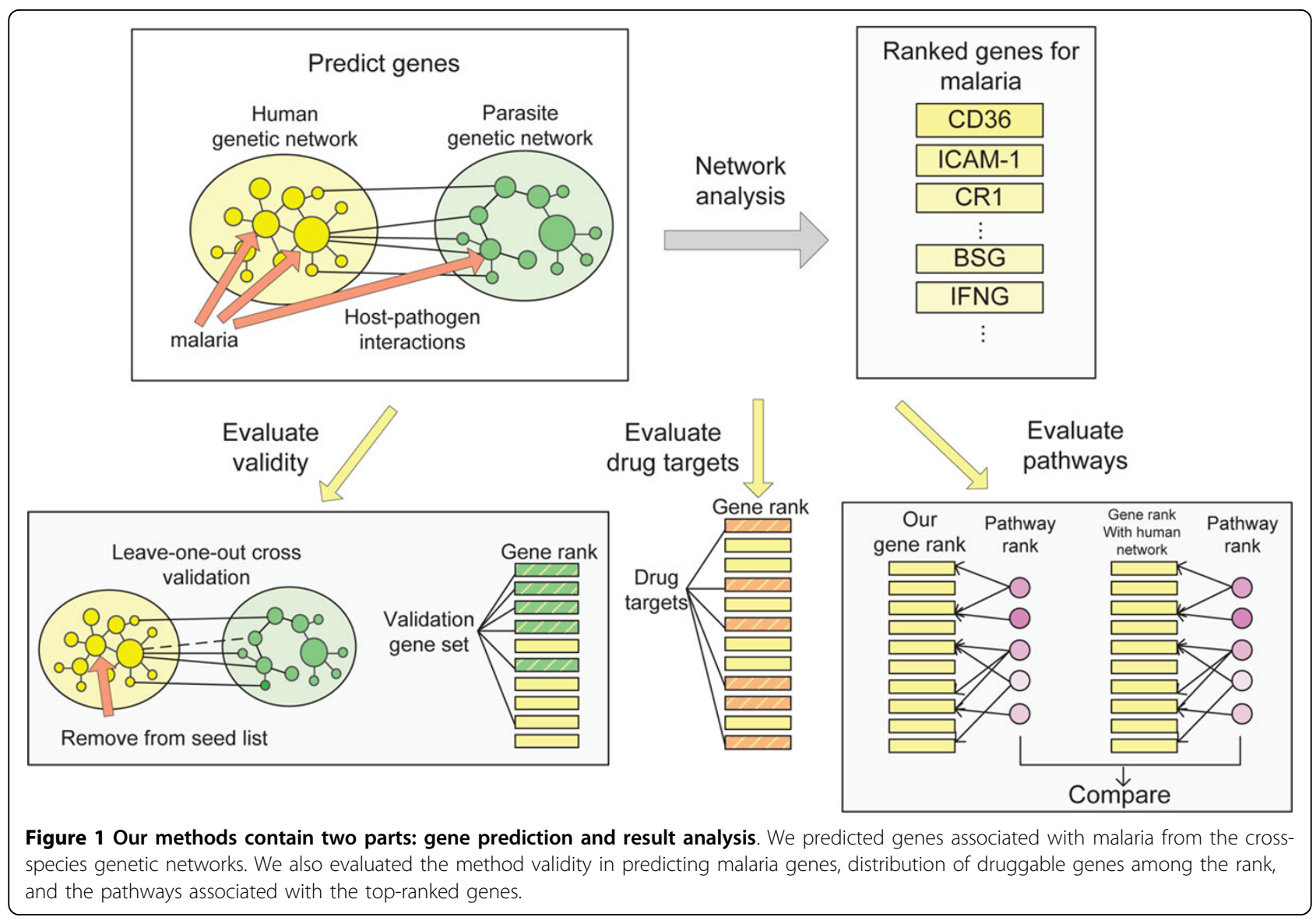


abstracts, curated pathway databases and co-expressed genes. We used the four sources to build comprehensive networks for both human and Plasmodium falciparum. The human network contains 20,770 proteins and 4,850,628 interactions; and the Plasmodium falciparum network contains 4,913 proteins and 1,007,938 interactions. In addition, we used the scores from STRING to weight the edges in the two genetic networks.

We connected these two protein networks with 36 interactions from PathogenPortal [52] and literature $[29,30,33]$. These interactions are binary and cover physical associations, direct interactions and chemical reactions between the two species. The interaction pairs from literature were curated manually. We unified the gene identifiers with the genetic networks for human and parasites through HUGO Gene Nomenclature Committee [53] and PlasmoDB [54].

\section{Predict candidate genes for malaria}

We manually collected 77 known malaria genes and used them as the seeds in our algorithm to find additional malaria genes. Among the 77 seed genes, 14 human genes were extracted from Online Mendelian Inheritance in Man (OMIM). In addition, extensive literature evidence suggests that the Plasmodium falciparum proteins-PfEMP1 [55-57], PfRh4 [38,58,59] and PfRh5 [60-62]- are essential for parasite growth and red blood cell invasion. We extracted 63 parasite genes encoding these three proteins and added them into the seed list.

We initiated a random walk on the cross-species genetic network from the seeds, and ranked all the genes by the probabilities of being reached from the seeds. We extended the algorithm by regulating the movements of the random walker between networks with the jumping probabilities $\lambda$. We represented the human and parasite genetic network with $H$ and $P$, respectively. When the random walker stands on a node in $H$, which is connected with a node in $P$, it may jump to $P$ with the probability $\lambda$ or stay in $H$ with the probability of $1-\lambda$.

We calculated the ranking scores for each node as follows. Assume $p 0$ is a vector of initial scores for each node, $p_{k}$ is the score vector at step $\mathrm{k}$ and was iteratively updated by:

$$
p_{k+1}=(1-\gamma) M^{T} p_{k}+\gamma p_{0}
$$

where $\gamma$ is the probability that the random walker restarts from the seeds at each step, and $M$ is the transition matrix of the cross-species genetic network:

$$
M=\left[\begin{array}{cc}
M_{H} & M_{H P} \\
M_{H P^{T}} & M_{P}
\end{array}\right] \text {. }
$$

The diagonal sub-matrices $M_{H}$ and $M_{P}$ consist of intra-network transition probabilities and were calculated as:

$$
\left(M_{i}\right)_{k l}=(1-\lambda x)\left(A_{i}\right)_{k l} / \sum_{l}\left(A_{i}\right)_{k l}
$$

where $i \in\{H, P\}, A_{i}$ is the adjacency matrix of the network $H$ or $P, k$ is the index of row, $l$ is the index of column, and $x$ is an indicator variable, which equals to 1 if $\sum_{l}\left(A_{i}\right)_{k l} \neq 0$ and 0 otherwise. The off-diagonal submatrices $M H P$ and MHP T consist of inter-network transition probabilities and were calculated as:

$$
\left(M_{j}\right)_{k l}=\lambda x\left(A_{j}\right)_{k l} / \sum_{l}\left(A_{j}\right)_{k l^{\prime}}
$$

where $j \in\left\{H P, H P^{T}\right\}$ and $\times$ is the same indicator variable. While the method could obtain a score for each human and parasite gene, we focus on ranking and analyzing the human genes in this study.

\section{Evaluate the validity in predicting malaria genes}

Before we used our method to predict genes for malaria, we performed the "leave-one-out" cross validation analysis to validate the method. Each time, we left out one malaria gene from the seed list, used the rest seeds as the input, and examined the rank of the excluded seed among the genes from the human or parasite genome. We repeated the same procedure for each of the 77 seeds, and assumed that the excluded seeds can be ranked highly if the method works well.

Then we used all the 77 seeds as the input, and evaluated if our gene ranking can prioritize novel malaria genes (other than the seeds). We manually constructed an independent set of 27 human genes involving malaria resistance and the host immune responses triggered by malaria parasites. These genes were extracted from literature references, which were mentioned in the textual descriptions of malaria in OMIM, and have zero overlap with the seed genes. We used this set as a proxy of novel malaria genes and evaluated the rank of this gene set among all human genes.

\section{Evaluate the ranks of druggable genes}

Currently, only a subset of the human genome is druggable [63]. In this study, we investigated if the topranked genes represent opportunities for drug discovery for malaria. We first extracted 1,935 human genes that were targets of all drugs from DrugBank [64]. All these drug target genes appear in our genetic network and have no overlap with the seeds. We used all 77 seeds as the input and ranked the human genes. Then we calculated the number of target genes among every 500 human genes in the rank from the top to the bottom, and plotted the variation of this number. 
Extract and analyze malaria-specific pathways based on gene ranking

To better understand the functions of the prioritized genes, we linked the top $10 \%$ of human genes to their pathways. We downloaded 1320 canonical pathways from MSigDB [65] and ranked them based on the average of random walk scores for all the genes in each pathway. We manually examined if the top pathways are associated with the host response to the pathogen invasion.

In addition, we evaluated the impact of introducing the parasite genome into our gene prediction method. We removed the parasite genetic network and hostparasite interactions from our method, and calculated the random walk scores for human genes. Then we re-ranked the pathways containing the top $10 \%$ genes again. We compared the rank of pathways before and after using the parasite genetic network, and extracted the ones with largest rank difference.

\section{Result}

Network-based approach allowed the prioritization of known malaria genes from both human and parasite genomes

Among the 77 seed genes, 14 were human genes and 63 were parasite genes. We evaluated the performances of our algorithms in ranking human and parasite seed genes separately with a leave-one-out cross validation analysis. Our method required two parameters: the jumping probability $\lambda$ between human and parasite genetic networks and the probability $\gamma$ that the random walker restarts from the seeds. We chose $\lambda=0.8$ and $\gamma=0.3$ to achieve the best performance in the cross validation, but different parameter values only slightly affect the result. We used the same values for the two parameters through all the analyses.

Table 1 shows that the ranks of the excluded human seed genes were high. In nine cases, the excluded genes directly interact with another seed and were ranked within the top $1 \%$ amongst all the human genes. Of these, two genes (CD36, ICAM1) were ranked in the top five. In 13 out of 14 cases, the excluded genes were ranked within top $3 \%$. The average rank for the excluded human seed genes is 336 (top 2\% among all human genes).

We also evaluated the 63 parasite seed genes, and our approach ranked the excluded nodes within the top 5\% in 56 out of 62 cases. Table 2 shows the top 10 parasite genes and their ranks in the cross validation. The average rank for the excluded parasite genes is 199 (top 4\% among all parasite genes). Less comprehensive data in the parasite genome than in the human genome may contribute to the lower rank (in percentage) of the parasite seed genes. Overall, this analysis demonstrated the
Table 1. Result of the leave-one-out cross validation for human genes

\begin{tabular}{lll}
\hline Gene symbol & Rank & Top percentage \\
\hline CD36 & 1 & $0.00 \%$ \\
ICAM1 & 2 & $0.01 \%$ \\
CR1 & 14 & $0.07 \%$ \\
SLC4A1 & 78 & $0.44 \%$ \\
NOS2 & 99 & $0.55 \%$ \\
GYPC & 121 & $0.67 \%$ \\
HBB & 126 & $0.70 \%$ \\
GYPA & 137 & $0.76 \%$ \\
FCGR2B & 159 & $0.88 \%$ \\
CISH & 232 & $1.29 \%$ \\
TIRAP & 277 & $1.54 \%$ \\
G6PD & 378 & $2.11 \%$ \\
FCGR2A & 403 & $2.25 \%$ \\
TNF & 2679 & $14.9 \%$ \\
\hline
\end{tabular}

We left out one malaria gene from the seed list each time, and determined the rank of this excluded gene using our method. We showed the rank and percentage among all human genes.

utility of the extended random walk to accurately prioritize known malaria genes.

\section{Network-based approach prioritized novel malaria genes} other than the seeds

Large amounts of literature have demonstrated strong associations between individual genes and malaria through transcriptional profiling, biological experimenting and genome-wide association studies. These genes include inflammatory responding genes, such as $\mathrm{NF} \kappa \mathrm{B}$ and CXCL1 [66], parasite protein receptors, such as BSG [67] and PROCR [57], and the genes involving protection against malaria, such as HLA-B [68] and HAVCR1 [69]. We then used all the seeds to generate our ranking for human genes, and examined the rank of 27 malaria genes, which have been validated in previous published studies. Table 3 shows that 12 out of 27

Table 2. Top 10 parasite genes in the leave-one-out cross validation

\begin{tabular}{lll}
\hline Gene (ORF name) & Rank & Top percentage \\
\hline PFD1235W & 18 & $0.37 \%$ \\
PF11 0521 & 22 & $0.45 \%$ \\
PF13 0003 & 29 & $0.59 \%$ \\
PFD0995C & 49 & $0.99 \%$ \\
PFL1955W & 49 & $0.99 \%$ \\
PFL1950W & 50 & $1.01 \%$ \\
PF07 0050 & 52 & $1.05 \%$ \\
PF07 0051 & 53 & $1.07 \%$ \\
PFD0630C & 53 & $1.07 \%$ \\
PFD1150C & 55 & $1.11 \%$ \\
\hline
\end{tabular}


Table 3. Rank of other malaria-associated genes from literature

\begin{tabular}{lll}
\hline Gene symbol & Rank & Top percentage \\
\hline BSG & 15 & $0.08 \%$ \\
IL6 & 20 & $0.11 \%$ \\
IFNG & 25 & $0.14 \%$ \\
IL1B & 34 & $0.19 \%$ \\
IL10 & 38 & $0.21 \%$ \\
IL8 & 65 & $0.36 \%$ \\
IL4 & 66 & $0.37 \%$ \\
ILIA & 137 & $0.77 \%$ \\
CD40LG & 142 & $0.79 \%$ \\
HLA-DRB1 & 145 & $0.81 \%$ \\
HLA-B & 168 & $0.94 \%$ \\
HAVCR2 & 179 & $0.99 \%$ \\
FUT9 & 183 & $1.02 \%$ \\
NF $\kappa$ B1 & 219 & $1.22 \%$ \\
HBA1 & 221 & $1.23 \%$ \\
HBA2 & 227 & $1.27 \%$ \\
HLA-DQB1 & 230 & $1.28 \%$ \\
HAVCR1 & 319 & $1.78 \%$ \\
GNAS & 358 & $1.99 \%$ \\
IFNGR1 & 380 & $2.12 \%$ \\
CXCL1 & 381 & $2.12 \%$ \\
MBL2 & 444 & $2.48 \%$ \\
CCL20 & 494 & $2.76 \%$ \\
IL12B & 499 & $2.79 \%$ \\
IFNAR1 & 954 & $5.33 \%$ \\
PROCR & 1515 & $8.46 \%$ \\
IL22 & 2467 & $13.8 \%$ \\
\hline & &
\end{tabular}

genes were ranked within the top $1 \%$, and a total of 24 genes within the top $5 \%$.

We also manually examined the top 50 human genes and found interesting predictions. Among them, TLR4 has been suggested to be protective against malaria in certain populations [70,71]. In addition, a recent mouse model experiment [72] has demonstrated that P53 was critical in the liver-stage infection of malaria. Together, the result demonstrated that our gene ranking prioritized novel malaria-associated genes other than the seeds.

\section{Prioritized genes are enriched by druggable genes}

Figure 2 shows that the top-ranked genes are enriched for drug targets. The top 500 human genes in our ranking have 235 overlaps with the drug targets, which is a 4.3 fold enrichment compared with the average of 100 random rankings $\left(p<10^{-8}\right)$. Among the 235 druggable genes, only 5 have been targeted by FDA-approved anti-malaria drugs, such as chloroquine, proguanil and mefloquine. This result indicated that the top-ranked candidate genes for malaria may provide unique opportunities for malaria drug discovery through novel disease genetics.

\section{Pathway analysis shows functions of prioritized genes} In order to gain insight into the commonalities underlying predicted malaria candidate genes, we analyzed the pathways associated with top-ranked genes. The topranked pathways are associated with different aspects of malaria. For example, malaria parasites actively alter the immune function of B cells and BIOCARTA BLYMPHOCYTE PATHWAY [73]. BIOCARTA LYM PATHWAY is a pathway of lymphocytes adhesion, and plays a central role in binding bacteria, parasites, viruses and tumor cells [74]. Also, BIOCARTA STEM PATHWAY regulates the hematopoiesis and induce hematopoietic activities in the presence of infection [75].

We compared the pathway ranking before and after introducing the parasite genetic network and found nine pathways increased the rank by over $50 \%$. Table 4 lists these pathways and their plausible associations with malaria pathogenesis and protection. Several of these pathways are directly related with the parasite infection and inflammatory responses. REACTOME BASIGIN INTERACTIONS was prioritized through the interaction with the parasite protein PfRh5. Other pathways that were brought up by less than $50 \%$ also may have associations with malaria. For example, the rank of the REACTOME HDL MEDIATED LIPID TRANSPORT pathway were improved by $40 \%$. A recent meta-analysis showed that host lipid profile alteration has a link with malaria pathogenesis, though the precise pathway has not been elucidated yet [76].

\section{Discussion}

Malaria is caused by the invasion of deadly parasites into human skin, liver and blood. The parasites trigger the human immune responses, but can manipulate human cells for nutrient uptake and cell growth. Recent studies have shown that host-pathogen protein interactions illuminate the malaria-specific pathways in the human host. With the accumulation of data in both human and parasite genome, systematically analyzing these two interacting genomes may potentially discover new malaria-associated genes, which will pave the way to identify novel anti-malaria drugs.

We developed a data-driven method to infer malaria genes based on random walking on the cross-species genetic networks. We demonstrated that the method can prioritize genes that are both drug targets and associated with malaria. Through comparing the result before and after adding the parasite genetic network into our method, we extracted specific pathways involving human-parasite interactions.

Our approach can be improved with a more comprehensive database of host-pathogen protein interactions. We currently manually curated 36 interactions, mostly from literature, to connect the human and parasite 


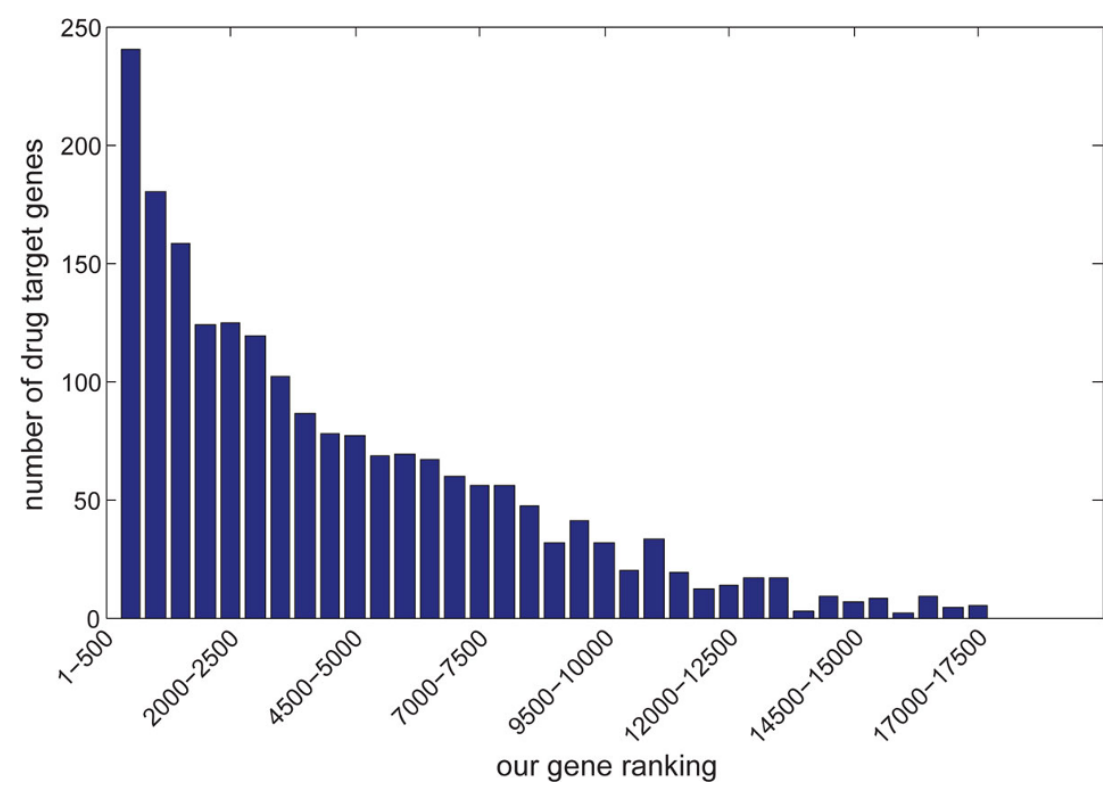

Figure 2 The count of drug target genes among every $\mathbf{5 0 0}$ genes in our rank from the top to the bottom.

genetic network. Compared with the humanhuman protein interactions, the coverage of humanparasite interaction is much lower and might be biased. As more data are introduced into the method, the global structure of the cross-species genetic network may change, which will affect the result of gene ranking. In the future, we plan to automatically mine the human-parasite interaction from literature and construct a database with better coverage.

Since our approach prioritized a set of druggable genes, which are associated with malaria, one example of subsequent work is to perform drug repositioning through matching the targets of approved drugs to predicted genes. In this way, however, a part of the candidate drugs may target generic inflammatory responses and may not be specific enough to kill the parasites. In addition, malaria is associated with different pathways when human are infected by different parasite species (other than Plasmodium falciparum) or different strains [28]. To develop more effective agents against malaria, we need to dissect the genetic basis using more specific data.

\section{Conclusions}

The lack of effective anti-malaria drugs and the poorlyunderstood disease genetics has motivated our study of detecting novel malaria-associated genes from both human and parasite genomes, with the ultimate goal of discovering innovative anti-malaria drugs based on a new

Table 4. Pathways prioritized over $50 \%$ in rank

\begin{tabular}{l} 
Pathway \\
\hline REACTOME PYRUVATE METABOLISM \\
REACTOME BASIGIN INTERACTIONS \\
PID SYNDECAN1 PATHWAY \\
REACTOME PYRUVATE METABOLISM AND \\
CITRIC ACID TCA CYCLE \\
REACTOME INTEGRIN CELL SURFACE \\
INTERACTIONS \\
REACTOME CELL SURFACE INTERACTIONS AT \\
THE VASCULAR WALL \\
BIOCARTA VDR PATHWAY
\end{tabular}

BIOCARTA MONOCYTE PATHWAY Potential association with malaria

Pyruvate kinase deficiency protect against malaria [77]

Basigin is a receptor essential for erythrocyte invasion by Plasmodium falciparum [67]

Induced by parasite infection [78]

Pyruvate kinase deficiency protect against malaria [77] and citric acid cycle activity involves chloroquine resistance [79]

Associated with Plasmodium induced thrombocytopenia [80]

Associated with red blood cell adhesion to the endothelial cell and cerebral malaria $[81,82]$

Control cellular nutrient uptake, differentiation, apoptosis, which may be affected by parasites $[13,83]$

Recruitment and activation of monocytes and macrophages are essential for both protection and pathology in malaria-infected individuals [84]

REACTOME PLATELET ADHESION TO EXPOSED COLLAGEN

Platelet adhesion and aggregation may play important roles in facilitating adhesion of infected red blood cells [85-87] 
genetic understanding of the disease. We developed a data-driven approach to infer malariaassociated genes. Since malaria is caused by the interactions between parasites and human, we constructed a cross-species genetic network to model these interactions, and prioritized relative genes using network analysis. We demonstrated the validity of the method in predicting malaria genes, and showed the potential of the predicted genes in drug discovery. We also extracted pathways from the result of gene ranking, and found these pathways reflect different aspects of malaria pathogenesis.

\section{Competing interests}

The authors declare that they have no competing interests.

\section{Authors' contributions}

RX conceived the study. YC designed the methods, performed the experiments and wrote the manuscript. Both authors have participated study discussion and manuscript preparation.

\section{Declarations}

Publication charges for this article have been funded by the Training grant in Computational Genomic Epidemiology of Cancer (CoGE) (R25 CA094186-06). This article has been published as part of BMC Genomics Volume 16 Supplement 7, 2015: Selected articles from The International Conference on Intelligent Biology and Medicine (ICIBM) 2014: Genomics. The full contents of the supplement are available online at http://www.biomedcentral.com/ bmcgenomics/supplements/16/S7.

\section{Authors' details}

'Department of Epidemiology and Biostatistics, Case Western Reserve University, Cleveland, OH, USA. ${ }^{2}$ Department of Electrical Engineering and Computer Science, Case Western Reserve University, Cleveland, OH, USA.

Published: 11 June 2015

\section{References}

1. World Health Organization. World Malaria Report 2013. [http://www.who. int/malaria/publications/world malaria report 2013/en/].

2. Kar S, Kar S: Control of malaria. Nature Reviews Drug Discovery 2010, 16(7):511-512.

3. Biamonte MA, Wanner J, Le Roch KG: Recent advances in malaria drug discovery. Bioorg Med Chem Lett 2013, 23(10):2829-2843.

4. Murray CJ, Rosenfeld LC, Lim SS, Andrews KG, Foreman KJ, Haring D, et al: Global malaria mortality between 1980 and 2010: a systematic analysis. The Lancet 2012, 379(9814):413-431.

5. Kim Y, Schneider K: Evolution of drug resistance in malaria parasite populations. Nature Education Knowledge 2013, 4(8):6.

6. Dondorp AM, Nosten F, Yi P, Das D, Phyo AP, Tarning J, Lwin KM, Ariey F, Hanpithakpong W, Lee SJ, et al: Artemisinin resistance in Plasmodium falciparum malaria. New England Journal of Medicine 2009, 361(5):455-467.

7. Miller LH, Ackerman HC, Su Xz, Wellems TE: Malaria biology and disease pathogenesis: insights for new treatments. Nature Med 2013, 19(2):156-167.

8. Horn D, Duraisingh MT: Antiparasitic chemotherapy: From genomes to mechanisms. Pharmacology and Toxicology 2014, 54(1):71-94.

9. Flannery EL, Chatterjee AK, Winzeler EA: Antimalarial drug discovery [MDASH] approaches and progress towards new medicines. Nature Reviews Microbiology 2013, 11(12):849-862.

10. Hanson KK, Ressurreicao AS, Buchholz K, Prudencio M, Herman-Ornelas JD, Rebelo $\mathrm{M}$, et al: Torins are potent antimalarials that block replenishment of Plasmodium liver stage parasitophorous vacuole membrane proteins. Proceedings of the National Academy of Sciences 2013, 110(30):2838-2847.

11. Ariey F, Witkowski B, Amaratunga C, Beghain J, Langlois AC, Khim N, et al: A molecular marker of artemisinin-resistant Plasmodium falciparum malaria. Nature 2014, 505(7481):50-55.
12. Kwiatkowski DP: How malaria has affected the human genome and what human genetics can teach us about malaria. The American Journal of Human Genetics 2015, 77(2):171-192.

13. Menard R, Tavares J, Cockburn I, Markus M, Zavala F, Amino R: Looking under the skin: the first steps in malarial infection and immunity. Nature Reviews Microbiology 2013, 11(10):701-712.

14. Crompton PD, Moebius J, Portugal S, Waisberg M, Hart G, Garver LS, et al: Malaria immunity in man and mosquito: Insights into unsolved mysteries of a deadly infectious disease*. Annu Rev Immunol 2014 32:157-187.

15. Zheng H, Tan Z, Xu W: Immune evasion strategies of pre-erythrocytic malaria parasites. Mediators of Inflammation 2014, 2014.

16. Engwerda CR, Kumar R: Mast cells fuel the fire of malaria immunopathology. Nature Med 2013, 19(6):672-674.

17. Kaushansky A, Metzger P, Douglass A, Mikolajczak S, Lakshmanan V, Kain H, Kappe SH: Malaria parasite liver stages render host hepatocytes susceptible to mitochondria-initiated apoptosis. Cell Death Dis 2013, 4(8): e762.

18. Sicard A, Semblat JP, Doerig C, Hamelin R, Moniatte M, Dorin-Semblat D, et al: Activation of a PAK-MEK signalling pathway in malaria parasiteinfected erythrocytes. Cell Microbiol 2011, 13(6):836-845.

19. Austin LS, Kaushansky A, Kappe SH: Susceptibility to Plasmodium liver stage infection is altered by hepatocyte polyploidy. Cellular Microbiol 2014, 16(5):784-795.

20. Khor CC, Hibberd ML: Revealing the molecular signatures of hostpathogen interactions. Genome Biol 2011, 12(10):229.

21. Gardner MJ, Hall N, Fung E, White O, Berriman M, Hyman RW, et al: Genome sequence of the human malaria parasite Plasmodium falciparum. Nature 2002, 419(6906):498-511.

22. Elsworth B, Matthews K, Nie CQ, Kalanon M, Charnaud SC, Sanders PR, et al: PTEX is an essential nexus for protein export in malaria parasites. Nature 2014, 511(7511):587-591.

23. Beck JR, Muralidharan V, Oksman A, Goldberg DE: PTEX component HSP101 mediates export of diverse malaria effectors into host erythrocytes. Nature 2014, 511(7511):592-595.

24. Bongfen SE, Laroque A, Berghout J, Gros P: Genetic and genomic analyses of host-pathogen interactions in malaria. Trends Parasitol 2009, 25(9):417-422.

25. Hedrick PW: Population genetics of malaria resistance in humans. Heredity 2011, 107(4):283-304.

26. Driss A, Hibbert JM, Wilson NO, labal SA, Adamkiewicz TV, Stiles JK: Genetic polymorphisms linked to susceptibility to malaria. Malar J 2011, 10:271.

27. Venkatesh S, Workman JL, Wahlgren M, Bejarano MT: Malaria: Molecular secrets of a parasite. Nature 2013, 499(7457):156-157.

28. Wu J, Tian L, Yu X, Pattaradilokrat S, Li J, Wang M, et al: Strain-specific innate immune signaling pathways determine malaria parasitemia dynamics and host mortality. Proceedings of the National Academy of Sciences 2014, 111(4):E511-E520.

29. Janes JH, Wang CP, Levin-Edens E, Vigan-Womas I, Guillotte M, Melcher $M$, et al: Investigating the host binding signature on the plasmodium falciparum PfEMP1 protein family. PLoS Pathog 2011, 7(5):e1002032.

30. Robinson BA, Welch TL, Smith JD: Widespread functional specialization of Plasmodium falciparum erythrocyte membrane protein 1 family members to bind CD36 analysed across a parasite genome. Molecular Microbiol 2003, 47(5):1265-1278.

31. Baruch DI, Ma XC, Pasloske B, Howard RJ, Miller LH: CD36 peptides that block cytoadherence define the CD36 binding region for Plasmodium falciparum-infected erythrocytes. Blood 1999, 94(6):2121-2127.

32. Baruch DI, Gormely JA, Ma C, Howard RJ, Pasloske BL: Plasmodium falciparum erythrocyte membrane protein 1 is a parasitized erythrocyte receptor for adherence to $\mathrm{CD} 36$, thrombospondin, and intercellular adhesion molecule 1. Proceedings of the National Academy of Sciences 1996, 93(8):3497-3502.

33. Bengtsson A, Joergensen $L$, Rask TS, Olsen RW, Andersen MA, Turner $L$, et al: A novel domain cassette identifies plasmodium falciparum PFEMP1 proteins binding ICAM- 1 and is a target of cross-reactive, adhesioninhibitory antibodies. The Journal of Immunology 2013, 190(1):240-249.

34. Smith JD, Craig AG, Kriek N, Hudson-Taylor D, Kyes S, Fagen T, et al: Identification of a Plasmodium falciparum intercellular adhesion molecule-1 binding domain: a parasite adhesion trait implicated in cerebral malaria. Proceedings of the National Academy of Sciences 2000, 97(4):1766-1771. 
35. Brown A, Turner L, Christoffersen S, Andrews KA, Szestak T, Zhao Y, et al: Molecular architecture of a complex between an adhesion protein from the malaria parasite and intracellular adhesion molecule 1. Journal of Biological Chemistry 2013, 288(8):5992-6003.

36. Chakravorty S, Hughes $K$, Craig A: Host response to cytoadherence in Plasmodium falciparum. Biochemical Society Transactions 2008, 36(Pt 2):221-228.

37. Medana IM, Turner GD: Human cerebral malaria and the blood-brain barrier. Int J Parasitol 2006, 36(5):555-568.

38. Tham WH, Wilson DW, Lopaticki S, Schmidt CQ, Tetteh-Quarcoo PB, Barlow PN, et al: Complement receptor 1 is the host erythrocyte receptor for Plasmodium falciparum PfRh4 invasion ligand. Proceedings of the National Academy of Sciences 2010, 107(40):17327-17332.

39. Spadafora C, Awandare GA, Kopydlowski KM, Czege J, Moch JK, Finberg RW et al: Complement receptor 1 is a sialic acid-independent erythrocyte receptor of Plasmodium falciparum. PLoS Pathogens 2010, 6(6):e1000968

40. Barabasi AL, Gulbahce N, Loscalzo J: Network medicine: a network-based approach to human disease. Nature Reviews Genetics 2011, 12(1):56-68.

41. Kohler S, Bauer S, Horn D, Robinson PN: Walking the interactome for prioritization of candidate disease genes. The American Journal of Human Genetics 2008, 82(4):949-958.

42. Wang X, Gulbahce N, Yu H: Network-based methods for human disease gene prediction. Brief Funct Genomics 2011, 10(5):280-293.

43. Aerts S, Lambrechts D, Maity S, Van Loo P, Coessens B, De Smet F, et al: Gene prioritization through genomic data fusion. Nature Biotechnol 2006, 24(5):537-544.

44. Lage K, Karlberg EO, Størling ZM, Olason PI, Pedersen AG, Rigina O, et al: A human phenome-interactome network of protein complexes implicated in genetic disorders. Nature Biotechnol 2007, 25(3):309-316.

45. Wu X, Jiang R, Zhang MQ, Li S: Network-based global inference of human disease genes. Mol Syst Biol 2008, 4(1):189.

46. Li Y, Patra JC: Genome-wide inferring gene-phenotype relationship by walking on the heterogeneous network. Bioinformatics 2010, 26(9):1219-1224

47. Wu X, Liu Q, Jiang R: Align human interactome with phenome to identify causative genes and networks underlying disease families. Bioinformatics 2009, 25(1):98-104.

48. Vanunu O, Magger O, Ruppin E, Shlomi T, Sharan R: Associating genes and protein complexes with disease via network propagation. PLOS Comput Biol 2010, 6(1):e1000641.

49. Gandhi T, Zhong J, Mathivanan S, Karthick L, Chandrika K, Mohan SS, et al: Analysis of the human protein interactome and comparison with yeast worm and fly interaction datasets. Nature Genetics 2006, 38(3):285-293.

50. Franceschini A, Szklarczyk D, Frankild S, Kuhn M, Simonovic M, Roth A, et al: String v9. 1: protein-protein interaction networks, with increased coverage and integration. Nucleic Acids Res 2013, 41(D1):808-815.

51. Snel B, Lehmann G, Bork P, Huynen MA: String: a web-server to retrieve and display the repeatedly occurring neighbourhood of a gene. Nucleic Acids Res 2000, 28(18):3442-3444.

52. Aurrecoechea C, Brestelli J, Brunk BP, Fischer S, Gajria B, Gao X, et al: EuPathDB: a portal to eukaryotic pathogen databases. Nucleic Acids Res 2010, 38(Database issue):D415-D419.

53. Gray KA, Daugherty LC, Gordon SM, Seal RL, Wright MW, Bruford EA: Genenames. org: the hgnc resources in 2013. Nucleic Acids Res 2012, , Database issue: D545-D552.

54. Aurrecoechea C, Brestelli J, Brunk BP, Dommer J, Fischer S, Gajria B, et al: PlasmoDB: a functional genomic database for malaria parasites. Nucleic Acids Res 2009, 37(Database issue):D539-D543.

55. Pasternak ND, Dzikowski R: PfEMP1: An antigen that plays a key role in the pathogenicity and immune evasion of the malaria parasite Plasmodium falciparum. Int J Biochem Cell Biol 2009, 41(7):1463-1466.

56. Flick K, Chen Q: var genes, PfEMP1 and the human host. Mol Biochem Parasitol 2004, 134(1):3-9.

57. Turner L, Lavstsen T, Berger SS, Wang CW, Petersen JE, Avril M, et al: Severe malaria is associated with parasite binding to endothelial protein $C$ receptor. Nature 2013, 498(7455):502-505.

58. Park HJ, Guariento M, Maciejewski M, Hauhart R, Tham WH, Cowman AF et al: Using mutagenesis and structural biology to map the binding site for the Plasmodium falciparum merozoite protein PfRh4 on the human immune adherence receptor. Journal of Biological Chemistry 2014, 289(1):450-463.
59. Tham WH, Wilson DW, Reiling L, Chen L, Beeson JG, Cowman AF: Antibodies to reticulocyte binding protein-like homologue 4 inhibit invasion of Plasmodium falciparum into human erythrocytes. Infect Immun 2009, 77(6):2427-2435.

60. Williams AR, Douglas AD, Miura K, Illingworth JJ, Choudhary P, Murungi LM, et al: Enhancing blockade of Plasmodium falciparum erythrocyte invasion: assessing combinations of antibodies against PfRH5 and other merozoite antigens. PLoS Pathogens 2012, 8(11):e1002991.

61. Douglas AD, Williams AR, Illingworth JJ, Kamuyu G, Biswas S, Goodman AL, et al: The blood-stage malaria antigen PfRH5 is susceptible to vaccineinducible cross-strain neutralizing antibody. Nature Commun 2011, 2:601

62. Douglas AD, Baldeviano GC, Miura K, Wright GJ, Draper SJ: PfRH5 vaccine efficacy against heterologous strain blood-stage Plasmodium falciparum. The Lancet 2014, 383(Special issue):S43.

63. Hopkins AL, Groom CR: The druggable genome. Nat Rev Drug Discov 2002, 1(9):727-730.

64. Law V, Knox C, Djoumbou Y, Jewison T, Guo AC, Liu Y, et al: DrugBank 4.0: shedding new light on drug metabolism. Nucleic Acids Res 2014, 42(D1):1091-1097.

65. Subramanian A, Tamayo P, Mootha VK, Mukherjee S, Ebert BL, Gillette MA, et al: Gene set enrichment analysis: a knowledge-based approach for interpreting genome-wide expression profiles. Proc Natl Acad Sci U S A 2005, 102(43):15545-15550

66. Tripathi AK, Sha W, Shulaev V, Stins MF, Sullivan DJ: Plasmodium falciparum-infected erythrocytes induce NF-kappaB regulated inflammatory pathways in human cerebral endothelium. Blood 2009, 114(19):4243-4252.

67. Crosnier C, Bustamante LY, Bartholdson SJ, Bei AK, Theron M, Uchikawa M, et al: Basigin is a receptor essential for erythrocyte invasion by Plasmodium falciparum. Nature 2011, 480(7378):534-537.

68. Hill AV, Allsopp CE, Kwiatkowski D, Anstey NM, Twumasi P, Rowe PA, et al: Common west African HLA antigens are associated with protection from severe malaria. Nature 1991, 352(6336):595-600.

69. Nuchnoi P, Ohashi J, Kimura R, Hananantachai H, Naka I, Krudsood S, et al: Significant association between TIM1 promoter polymorphisms and protection against cerebral malaria in Thailand. Ann Hum Genet 2008, 72(3):327-336.

70. Ferwerda B, McCall MB, Alonso S, Giamarellos-Bourboulis EJ, Mouktaroudi M, Izagirre $N$, et al: TLR4 polymorphisms, infectious diseases, and evolutionary pressure during migration of modern humans. Proceedings of the National Academy of Sciences 2007, 104(42):16645-16650.

71. Sawian CE, Lourembam SD, Banerjee A, Baruah S: Polymorphisms and expression of TLR4 and 9 in malaria in two ethnic groups of Assam, northeast India. Innate Immunity 2013, 19(2):174-183.

72. Kaushansky A, Ye AS, Austin LS, Mikolajczak SA, Vaughan AM, Camargo N, et al: Suppression of host $\mathrm{p} 53$ is critical for Plasmodium liver-stage infection. Cell Reports 2013, 3(3):630-637.

73. Scholzen A, Sauerwein RW: How malaria modulates memory: activation and dysregulation of B cells in Plasmodium infection. Trends Parasitol 2013, 29(5):252-262.

74. Vestweber D, Blanks JE: Mechanisms that regulate the function of the selectins and their ligands. Physiological Reviews 1999, 79(1):181-213.

75. Abdalla S: Hematopoiesis in human malaria. Blood Cells 1989, 16(23):401-416.

76. Visser BJ, Wieten RW, Nagel IM, Grobusch MP: Serum lipids and lipoproteins in malaria-a systematic review and meta-analysis. Malaria Journal 2013, 12(1):442.

77. Ayi K, Min-Oo G, Serghides L, Crockett M, Kirby-Allen M, Quirt l, et al: Pyruvate kinase deficiency and malaria. New England Journal of Medicine 2008, 358(17):1805-1810.

78. Beiting DP, Park PW, Appleton JA: Synthesis of syndecan-1 by skeletal muscle cells is an early response to infection with Trichinella spiralis but is not essential for nurse cell development. Infection and Immunity 2006, 74(3):1941-1943.

79. Howells R, Maxwell L: Citric acid cycle activity and chloroquine resistance in rodent malaria parasites: the role of the reticulocyte. Ann Trop Med Parasitol 1973, 67(3):285-300.

80. Campos FM, Santos ML, Kano FS, Fontes CJ, Lacerda MV, Brito CF, Carvalho LH: Genetic variability in platelet integrin a $2 \beta 1$ density: Possible contributor to Plasmodium vivax-induced severe thrombocytopenia. Am J Trop Med Hyg 2013, 88(2):325-328. 
81. Mota MM, Jarra W, Hirst E, Patnaik PK, Holder AA: Plasmodium chabaudiinfected erythrocytes adhere to CD36 and bind to microvascular endothelial cells in an organ-specific way. Infection and Immunity 2000, 68(7):4135-4144.

82. Nacer A, Movila A, Baer K, Mikolajczak SA, Kappe SH, Frevert U: Neuroimmunological blood brain barrier opening in experimental cerebral malaria. PLoS Pathogens 2012, 8(10):e1002982.

83. Zeba AN, Sorgho H, Rouamba N, Zongo I, Rouamba J, Guiguemd'e RT, et al: Major reduction of malaria morbidity with combined vitamin a and zinc supplementation in young children in burkina faso: a randomized double blind trial. Nutr J 2008, 7(7):7.

84. Chua CLL, Brown G, Hamilton JA, Rogerson S, Boeuf P: Monocytes and macrophages in malaria: protection or pathology? Trends in Parasitology 2013, 29(1):26-34

85. Grau GE, Mackenzie CD, Carr RA, Redard M, Pizzolato G, Allasia C, et al: Platelet accumulation in brain microvessels in fatal pediatric cerebral malaria. Journal of Infectious Diseases 2003, 187(3):461-466.

86. Pain A, Ferguson DJ, Kai O, Urban BC, Lowe B, Marsh K, Roberts DJ: Platelet-mediated clumping of Plasmodium falciparum-infected erythrocytes is a common adhesive phenotype and is associated with severe malaria. Proceedings of the National Academy of Sciences 2001, 98(4):1805-1810.

87. Wassmer SC, Lepolard C, Traore B, Pouvelle B, Gysin J, Grau GE: Platelets reorient Plasmodium falciparum-infected erythrocyte cytoadhesion to activated endothelial cells. Journal of Infectious Diseases 2004, 189(2):180-189.

\section{doi:10.1186/1471-2164-16-S7-S9}

Cite this article as: Chen and Xu: Network-based gene prediction for Plasmodium falciparum malaria towards genetics-based drug discovery. BMC Genomics 2015 16(Suppl 7):S9.

\section{Submit your next manuscript to BioMed Central and take full advantage of:}

- Convenient online submission

- Thorough peer review

- No space constraints or color figure charges

- Immediate publication on acceptance

- Inclusion in PubMed, CAS, Scopus and Google Scholar

- Research which is freely available for redistribution

Submit your manuscript at www.biomedcentral.com/submit
Biomed Central 